\title{
LA IRONÍA TRAGICÓMICA DE LO INTOTALIZABLE
}

\author{
Philippe Grosos*
}

El presente estudio intenta mostrar que la ironía tiene un valor ontológico, que le hace ser más que un simple rasgo de lenguaje o de espíritu. Así, describiendo la reversibilidad de nuestras situaciones de existencia, ella dice el sentido de ser de lo real y recalca dos determinaciones fundamentales: su carácter intotalizable y su potencia tragicómica. Para probar esta tesis nos apoyaremos tanto en el análisis de algunas obras literarias como en la inteligencia de los fenómenos.

Palabras clave: ironía tragicómica, intotalizable, real.

THE TRAGICOMIC IRONY OF THE NON-TOTALIZABLE

The present study attempts to show that irony has an ontological value being more than just a feature of language or spirit. Thus, describing the reversibility of our existence situations, it tells the sense of being of reality and emphasizes two fundamental determinations: its non-totalizable character and tragicomic power. To prove this thesis we will support us both the analysis of literary works and the intelligence of the phenomena.

Keywords: tragicomic irony, non-totalizable, real.

*Universidad de Poitiers, Poitiers, Francia. Correo electrónico: philippe.grosos@orange.fr

Traductores: Enoc Muñoz (enocman@hotmail.com) y Patricio Mena Malet (pamenam@uahurtado.cl) 

BIOGRÁFICAMENTE INTOTALIZABLE: POR SU MUERTE QUE NO VIVIRÁ, por su nacimiento que no vivió, por la duración de su temporalización, de la que no domina ni la extensión ni la intensidad, por el acontecer que no cesa de sorprenderlo, así como por su relación con el otro -ese otro que él no puede ser y que siempre se le escapa-, el existente atraviesa irónicamente la existencia. Que sea así, no significa que la atraviese con una sonrisa sarcástica, con la distancia del hombre hastiado, si no despechado, cansado de todo y, en suma, fatigado. Ciertamente, más que experimentarla, de tal travesía hace la prueba; debido a que ella puede solicitar duramente a aquel que, no habiendo originariamente demandado nada, se descubre presente al otro y al mundo. Si tal es precisamente el caso, esto significa, entonces, que la ironía, de la que se trata aquí, no es un rasgo de carácter. Como la paciencia, que antes incluso de poder ser una virtud o simplemente un revelador de mi psicología, testimonia ontológicamente la necesaria temporalización de mi existencia, de mi duración en tanto que constantemente confrontada con aquella de las cosas mismas, la ironía me remite originariamente al tiempo, al otro, a mí, como lo que siempre se escapa, incluso cuando creo poder disponer de ello.

La ironía es la denuncia del fantasma de señorío, su inversión; y es como tal que arriba primeramente a la conciencia. Porque incluso antes de ser asunto de lenguaje o de comportamiento, antes incluso de ser la manifestación brillante de aquel que estila el ingenio y así se ríe del lenguaje a falta de poder reírse de lo real, la ironía es, como admirablemente ha podido decirlo Jankélévitch, aquello que "rinde homenaje a la temporalidad de la vida". "La ironía -escribe él-, es la inquietud y la vida inconfortable. [...] Quien se hace el sordo a su cuchicheo, se condena al dogmatismo estacionario y al embotamiento beato. Tieck le agradece que nos proteja de lo mágico y sus tentaciones. Todo se transforma, todo es mudable, fluyente, cambiante. La ironía protesta contra el racionalismo estático y rinde homenaje a la temporalidad de la vida; a su manera, la ironía dice que toda la esencia del ser es devenir, que no hay otra manera de ser más que aquella del deber-ser, que la conciencia es lo contrario que una cosa"1.

¿Acaso no es irónica la situación de ese ex gran deportista que se ha convertido en un impedido, o de ese cronista que se ha vuelto un amnésico? Ahí donde hubo poder, reina la impotencia; y ahí donde hubo señorío, la incapacidad. Pero la ironía no subraya solo la degradación de los cuerpos y espíritus. En efecto, ella no puede rendir "homenaje a la

1 JankélÉVitch, Vladimir, L'ironie ou la bonne conscience, PUF, Paris, 1950, p. 168. Traducción al español de José Luis Checa, La ironía, Taurus, Madrid, 1986. 
temporalidad de la vida" más que al resaltar igualmente su "creación continua de imprevisible novedad", como decía Bergson; quien fue maestro de Jankélévitch. Por ello, irónica es también la situación de aquel que, no teniendo nada, se encuentra provisto más allá de sus expectativas; de aquel que no esperando ya nada, es colmado.

Este incesante volcamiento que le caracteriza supone, pues, que siempre todo se transforma; que todo es mudable, fluyente, cambiante. Sin embargo, este permanente cambiar, lo que Montaigne nombraba a su manera un "tembladero perenne", no basta para pensar la ironía de las situaciones: el que todo cambie siempre en la duración no explica todavía la posibilidad de un volcamiento (retournement) de las situaciones de existencia. Todo podría simplemente devenir, alterarse. Lo que entonces no sería más que un modo de la constancia temporal. Pero la ironía protesta. Protesta, dice Jankélévitch, tomando prestada la fórmula de Robert Minder², "contra el racionalismo estático": ese que piensa la evolución como un desarrollo continuo, que hace de la existencia un largo río tranquilo que conduce del nacimiento a la muerte, que desconoce, en suma, la imprevisible novedad; es decir, que desconoce al acontecimiento en su capacidad de hacer surgir, a partir de lo inesperado, el antes y después en la duración propia. Y es que la ironía de la situación no requiere solamente el cambio permanente, requiere igualmente la imprevisibilidad del acontecimiento.

Y sin embargo, que lo real sea "siempre aquello que no se esperaba"3 -según la justa fórmula que Henri Maldiney no deja de meditar desde Mirada Palabra Espacio-, ello no es todavía suficiente para pensar su carácter irónico. Esto es así mientras su originaria imprevisibilidad no lo rinda como necesariamente revestido, no dé necesariamente nacimiento a situaciones en las cuales se produce el exacto contrario de aquello con lo que yo contaba, o también de aquello que precisamente buscaba evitar. Más que el constante cambio y más que con el sobrecogimiento del acontecimiento, la ironía me pone ante lo inasequible de lo real. Lejos de ser raros o excepcionales, tales volcamientos (revestimientos de situaciones), son las constantes imprevisibles de nuestras existencias que hacen las delicias de los mejores escritores: en ellos y por ellos la dramática de la historia está siempre asegurada. Que los escritores se prendan de estas situaciones no las convierte en irreales o imaginarias. Es, más bien, lo inverso lo verdadero. Precisamente, porque lo real sobrepasa el poder de imaginación de la ficción, es que esta puede querer recobrarlo; a veces estigmatizándolo, a veces traduciéndolo en la infinita precisión de sus detalles. De manera que, lejos de distanciarnos de lo real y de sumirnos en lo ficticio de la ficción, el rodeo por algunas obras podrá, por el contrario, y -si se piensa bien-, conducirnos a ello.

Es así que Shakespeare es innegablemente uno de los maestros de la ironía. Que la acción se sitúe en el corazón de una amable comedia, como en Penas de amor perdido,

2 Minder, Robert, Un poète romantique allemand. Ludwig Tieck, Les Belles Lettres, Paris, 1936, p. 320.

3 Maldiney, Henri, Regard Parole Espace, L'Age d'Homme, Lausanne, 1973. Esta fórmula se convierte en un leit motiv de esta obra. Cfr. pp. 19, 23, 117, 152, 182. 
donde aquellos que quieren sustraerse al amor se reencuentran, por él, atados; o que la acción se sitúe en la más oscura de sus tragedias, como en Macbeth, donde aquellos que asesinan y empujan al crimen terminan por ser ellos mismos obsesivamente perseguidos por la impureza indeleble de sus actos; cualquiera sea el caso, la ironía está ahí y reina casi totalmente. Ahora bien, esto lo encontramos también, aunque más descuidadamente pero no con menos pertinencia, en las obras de Ludwig Tieck, a quien menciona Jankélévitch.

En una de sus numerosas novelas, Der Jahrmarkt (La feria), editada en 1832, uno de los protagonistas de Tieck, el señor von Wandel, realiza esta extraña confesión: en un momento de su infancia, y aunque su padre tenía por él una verdadera predilección, su suerte cambiará completamente, llegando a un desorden ingobernable debido a algo que, al principio, no era más que una rara chifladura paternal, casi un juego. A este hombre se le había metido en la cabeza que, para facilitar su digestión, alguien debía exasperarlo. Dicha tarea le corresponderá a un criado que, es cierto, ya lo erizaba. Éste, entonces, se encargará de reportarle las maldades imaginariamente realizadas por su hijo. Como esto no estaba concebido más que para provocar artificialmente una afección, y como el hijo era verdaderamente querido, una vez favorecida la digestión, todo quedaba perdonado y olvidado. ¿Pero al jugar con fuego no termina uno quemándose? ¿Y no es éste el triunfo de la ironía: que aquello que en un comienzo es casi nada se convierta en algo cada vez más grande; que el juego se vuelva asunto serio, y que de la comedia nazca la tragedia como, por otro lado, de la tragedia la comedia? Sucedió, entonces, que el padre terminó por creer tan contundentemente las fabulaciones requeridas al doméstico, que, en unos meses, su amor para con el hijo "se había transformado en un odio mortal". Abrumado de reproches inverosímiles, viendo que su vida cotidiana se había convertido en un infierno, el niño debe esconderse "sin saber dónde encontrar socorro".

Ciertamente, toda ironía no es la manifestación de lo peor. Pero sí es la manifestación de la inaccesibilidad de lo real, de su carácter indomeñable, intotalizable, como lo recuerda a su modo (irónico también), un pastor en esta misma novela: "Es, claro, la alegoría más instructiva, -escribe entonces Tieck-, [...] de eso que todo lo que brilla no es oro, que habitualmente el diablo se oculta detrás de la cruz, que nada es menos natural que aquello que se dice es la naturaleza, que aquel que salió por lana podría terminar trasquilado, y que lo peor que puede sucederle es, como a este ermita, el ser esquilado permanentemente sin incluso tener lana en la piel, aunque pueda ser un cordero, tal vez un carnero"s.

Ahora bien, que sea un pastor quien enuncia aquí este derrumbamiento de todo señorío, ¿hace esto de la ironía la ley destinal de lo real? Afirmar lo real como esencialmente irónico, es, ciertamente, comprender que ningún existente puede sustraerse a esta ironía, precisamente porque nadie es señor de aquello que le adviene. Pero esto no quiere decir que la suerte se encuentre pre-destinalmente sellada, como si el despliegue de la exis-

4 Tieck, Ludwig, La foire, trad. de Nicole Taubes, Aubier, Paris, 1994, p. 77.

5 Ibid., p. 57. 
tencia no hiciera más que cumplirla ciegamente. Si hay ironía de lo real, ella no es sin embargo una ironía de la suerte, es decir, la realización de una intencionalidad divina más o menos laicizada. Tal consideración -que tal vez no reposa más que en el temor que prueba el existente con la idea de una existencia radicalmente abierta-, termina siempre, en efecto, por cerrar aquello que comenzaba a entreabrirse y por disimular aquello que ella comenzaba a entrever. Tal es la idea de la suerte, o aquella del destino ingenuamente formulada: alguien o algo ya ha ordenado o dominado para mí eso que yo mismo no podré ni ordenar ni dominar. Pero la suerte solo puede ser irónica permaneciendo abierta, fuera de todo señorío, y únicamente su recobramiento retrospectivo puede producir la ilusión de su predestinación.

Intotalizable, la ironía de ninguna manera podría ser clausurada sin negarse a sí misma. Es por esto que Jankélévitch escribe que su manera de ser "no es enciclopédica, sino elíptica. De un sistema cerrado se puede hacer un rodeo; pero una totalidad abierta no se aborda más que alusivamente. Aquí no hay circuito por finiquitar, sino, en profundidad, finezas que derrotan al análisis y, según magnitud, toda suerte de "ultrasonidos" o deste-

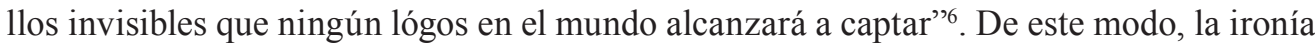
nos confronta con esas incesantes inversiones que no se pueden prever y que sin embargo hacen de lo real, precisamente, aquello en lo que se cree. La ironía, como lo dice también Jankélévitch, "es la alegría un poco melancólica que nos inspira el descubrimiento de una pluralidad"7. Si la pluralidad lo es de una realidad que sin cesar se me escapa, y que jamás puedo verdaderamente reunir y, por tanto, tampoco totalizar plenamente su sentido, en tal caso "la alegría un poco melancólica" que ella me inspira es lo que se abre en mis juegos de lenguaje y que se muestra en mis comportamientos. Esto es lo que traducen mis palabras tanto como mis maniobras irónicas en cuanto que son una respuesta a la originaria solicitación de una realidad por siempre intotalizable.

El que la acogida de lo intotalizable se pague al precio de una "alegría un poco melancólica”, es un hecho reconocido por todos los maestros de la ironía. Tal es el caso de ese gran ironista que fue Jean Paul. Por cierto, la ironía es del todo, primeramente, alegría. Y esto la distingue esencialmente de la burla que, en su Curso preparatorio de estética de 1804, Jean Paul piensa profundamente como "ironía de luz rasante [das ironische Streiflicht]". Luego, la amargura, como testimonio de la burla, es ya índice de una recepción de la apertura intotalizable de lo real que se ha vuelto difícil. E incluso cuando nuestra capacidad de acogida permanece intacta, la palabra irónica no es humorística. No apunta a hacer reír sino, lo que es muy distinto, a poner a distancia una realidad que, dichosa o

6 JankélÉVITCH, V., L'ironie ou la bonne conscience, op. cit., p. 81.

7 Ibid., p. 29.

8 PAul, Jean, Vorschule der Ästhetik, Carl Hanser, München, 1974, § 38, p. 156. Trad. al francés de: A.-M. Lang et J.-L. Nancy, Cours préparatoire d'esthétique, L’Age d'Homme, Lausanne, 1979, p. 154. La traducción al español está a cargo de P. Aullón de Haro, Introducción a la estética, Verbum, Madrid, 1991. Como norma general, hemos optado por traducir directamente de las versiones francesas que trabaja el autor, con el objetivo de resaltar lo más posible el sentido de los comentarios de éste. 
desdichada, se nos escapa. Poniéndola a distancia, la ironía no es entonces una gracia bribona, sino alegría. Esta alegría es, a su manera, un saber jovial, puesto que es el saber de una efectividad que se muestra y se me da como aquello con lo que yo no habría jamás terminado: como inagotable. Es por ello que Jean Paul anota: "si ha de existir un humor universal, la ironía de Platón [...] merecería el título de ironía universal [Welt-Ironie], ella que, musical y juguetona, no planea solamente por encima de los errores (como el humor no planea solamente por sobre extravagancias), sino de todo el saber; libre como una llama, devorante y regocijante, moviéndose con soltura y no impulsándose más que hacia el cielo"9. Pero siendo lo inagotable también intotalizable, cabe la posibilidad de que aquello con lo que no termino de habérmelas sea además aquello por lo que no llego jamás a comenzar. Así, el reverso de la alegría es aquí la melancolía que inevitablemente ella drena consigo.

Esta "alegría un poco melancólica" atraviesa enteramente la obra inclasificable de ese contemporáneo de Jean Paul que fue Jean Potocki. Obra en la que éste no ha dejado de hacer suya la experiencia de lo intotalizable. Rebelde a todo resumen, el extraordinario Manuscrito encontrado en Zaragoza tiene, a la vez, algo de novela picaresca como de relato abisal. Tiene el encanto oriental de Las mil y una noches, cuando por su escritura uno se encuentra confrontado con su incesante puesta en abismo, como si en el corazón de toda palabra germinara la inmensidad de todo aquello que queda todavía por decir y que ningún escrito jamás podrá totalizar.

En efecto, lo que caracteriza esencialmente a la obra de Potocki no es tanto la materia de su narración, entre relato fantástico y sincretismo religioso, como su modalidad misma, extraordinariamente abundante, hecha de imbricaciones de unos relatos en otros. Este encabalgamiento es tan complejo que frecuentemente, aquel que cuenta una historia, rodeado de orejas muy atentas, tal como Potocki las pone en escena, abre un paréntesis en el centro de su narración muy difícil de cerrar, por cuanto él mismo, a su vez, se deja extender por la contigüidad de otros relatos. Por esto, aquellos que la escuchan se asemejan a aquellos que se toman de esta novela: maltrechos, tan perdidos como fascinados por la amplitud de aquello que queda por decir (à dire). Se comprende así que esta imbricación de unos relatos en otros, no nace de una torpeza escritural, sino de una voluntariosa nueva manera de hacer sensible al lector, implicándolo y llevándolo a perderse en su lectura, en el carácter intotalizable del relato, de todo relato. Ahora bien, es esto lo que uno de los personajes de Potocki, Velásquez el geómetra, permite comprender explícitamente.

Velásquez es la caricatura del sabio distraído, esencialmente preocupado de poder echar las bases de un sistema a partir "de algún principio"10 fundamental salido de la geometría. De manera que, para él, se trata de transformar todo en ecuación. En efecto,

9 Ibid.

10 Ротоскі, Jean, Manuscrit trouvé à Saragosse, versión de 1804, edición establecida por F. Rosset y D. Triaire, GF, Paris, 2008, p. 409. 
la ecuación es a la vez aquello que, escrito bajo forma simbólica y, por tanto, de lectura más bien unívoca que polisémica, reúne y totaliza. La ecuación es la conquista unitaria y responsable de aquello que de otro modo no dejaría de darse en la diversidad posiblemente caótica, polivalente, de nuestra experiencia sensible del mundo. Así, con sus pretensiones explícitas de convertir todo en ecuación, hasta "la vida humana en general"", el relato nos hace frente como aquello que, intotalizable, se revela inasimilable.

Ahora bien, esto aparece primeramente a Velásquez como la prueba misma de la incoherencia, tal vez la insignificancia de la narración. "Tengo a bien prestar atención a los relatos de nuestro jefe, -le hace decir Potocki-, de los que ya no puedo comprender nada: ya no sé quien habla o quien escucha. Aquí es el marqués de Val Florida quien cuenta su historia a su hija que la cuenta al Bohemio que nos la cuenta. En verdad, esto es muy confuso. Siempre me ha parecido que las novelas y otras obras de este género debieran ser escritas sobre muchas columnas como los tratados de cronología". O también: "En verdad, temo en extremo esta historia; todas las del Bohemio comienzan con un aire muy simple y se espera verlas enseguida concluir: de ningún modo, una historia encierra otra que, a su vez, contiene una tercera, como esos restos de divisiones que se puede desarrollar en serie, y que en ciertos casos devienen infinitas. Pero se tiene los métodos para sumar casi todas las series. Mientras que si quiero hacer la suma de todo lo que dice Bohemio, no encuentro más que una extrema confusión"12.

A esta primera reacción sigue su voluntad de reconquistarse, de creer que si lo real se le escapa es porque todavía no ha sabido movilizar y dominar los útiles lógicos y conceptuales correctos, de creer que lo intotalizable no le indica más que su capacidad momentánea de totalizarlo. De lo que se trata, entonces, es de encontrar un procedimiento adecuado de puesta en forma: para el caso, una ley algebraica que permite rendir cuentas pertinentemente de la progresión y del encabalgamiento de los relatos. Es con esto que responde Velásquez a la pregunta del jefe de los bohemios, quien, viéndolo hacer los cálculos mientras hablaba, piensa que sus palabras le aburren: "Claro que no -responde Velásquez-, es, por el contrario, su historia lo que me mantiene ocupado. Este señor Iñigo Suárez tal vez encuentre en América a alguien que le cuente la historia de alguien que también tenía una historia que contar. Para esta deducción, he imaginado una escala de relación muy semejante a esa de la que se sirve para las secuencias recurrentes, llamadas así porque se recurre a ello como a los términos primeros. Continúe, pues, si le place"13.

Y sin embargo, es necesario resolverse a la evidencia: el cálculo no totaliza todo, tanto que la complejidad del encabalgamiento de los discursos escapa tanto a la racionalización como a la sumatoria algebraica. La versión de 1804 de esta obra, inacabada, pinta a 
un Velásquez más irritado que comprensivo frente a esta experiencia de lo intotalizable. Así, a un relato que el jefe de los bohemios se propone contar, él responde: "En buena hora [...], con tal que esas personas no hayan encontrado también a alguien que tenía una historia que contar; pues entonces me marcharía"14. No obstante, en la última versión de la misma obra - de 1810 y esta vez concebida como acabada-, Potocki presta a Velásquez otra lucidez. A Rebeca, que le pide que exponga su sistema, él le responde: "Madame [...], quizás sería precipitado hablarle de sistema. Esta palabra solo conviene a un conjunto de nociones ciertas, y estamos lejos de tenerlas. Somos unos ciegos que tocan algunos relieves y que conocen el cabo de algunas calles, pero que no necesitan darse el plano entero de la ciudad"15.

Se puede pensar que con esta respuesta la idea de una conquista de la totalidad de lo real como sistema no ha sido abandonada todavía, y que lo que con esto se pone en evidencia es nuestra incapacidad actual y puntual de concebirla y formularla bien. Sin embargo, como lo muestra otra historia de Potocki, no hay nada de eso. Lo intotalizable no es un hecho accidental, sino esencial, ya que nos construye el acceso a la manifestación de lo real.

Esta historia es la de Diegue Hervas que, en la versión de 1804 viene a concluir la obra, confiriendo así a su alegría, desde el seno de su ironía, una nota "un poco melancólica". Como Velásquez, Hervas es geómetra, y como él, intenta concebir el mundo como sistema. La manera como acoge esto es escribiendo una enciclopedia, una como la que soñaron los pensadores del Siglo de las Luces, más todavía que aquellos de la Época Medieval; una enciclopedia que, algunos años después, considerará haberla escrito. Ahora bien, a este sueño de una enciclopedia, es decir, de una totalización, Potocki va a oponer su ineficacia. Para Hervas el geómetra, todo comienza por un deseo de distracción, literalmente de evasión, cuando, encarcelado en Madrid como consecuencia de una lamentable confusión, "para aliviar su tedio, reflexiona haciendo un llamado mental a todos sus conocimientos, es decir, recordando lo que sabía de cada ciencia, y entonces se percata con gran satisfacción que había abrazado todo el conjunto de los conocimientos humanos, y que, como Pico de la Mirándola, él habría podido prepararse para sostener la tesis del omni scibili" ". Así, por la ambición "de hacerse un nombre en las ciencias", forma "en seguida el plan de una obra en cien volúmenes que debía contener todo lo que los hombres de su tiempo sabían" "17. Pero aquí distracción y ambición son malas consejeras, tanto así que adhiriéndose al juego de esta escritura insensata, Hervas se encontrará conducido, después de tres pruebas sucesivas, a su propia pérdida.

La primera de estas pruebas ocurre después de quince años de labor, tiempo en que acaba los cien volúmenes de su enciclopedia. Deseoso entonces de pasar algunos días en 
su ciudad natal de Asturias, deja allí la integridad de los libros recientemente encuadernados, antes de constatar, a su vuelta, que las ratas, atraídas por el olor del pegamento, han despedazado el conjunto de su trabajo; royendo, dispersando y mezclando todas las hojas de la obra. Aquí la totalidad, tan pronto constituida, se descubre privada de facticidad. Superado este primer momento de abatimiento, Hervas se pone nuevamente en obra con el fin de reunir y reconstituir su enciclopedia. Pero si después de ocho años de paciencia casi lo logra, nuevamente su sueño vendrá a romperse luego que, a través de los periódicos, se entere de los progresos realizados por las ciencias en el intertanto. Aquí la totalidad se revela factualmente inacabable. No obstante, Hervas, no comprendiéndolo claramente, supera esta segunda prueba trabajando de un tirón cuatro años suplementarios. Propone publicar entonces su obra acabada al librero Moreno, quien, después de haberla examinado, le pide reducir los cien volúmenes a veinticinco. Hervas, no pudiendo soportar esta tercera y última prueba, expulsa al librero y, cayendo "en la más negra melancolía"18, pone fin a sus días.

Lo que triunfa tras estas tres pruebas sucesivas, es la cruel ironía de la situación. Ciertamente, es posible pasarse la vida entera tratando de aprehender la totalidad de lo que es -Hervas persigue este proyecto durante veintisiete años antes de comprender que no llegará a ello-. Pero esta totalidad, de la que nunca se puede estar seguro que sea lo que ella dice ser, finalmente no interesa a nadie. Inactualizable, y rápidamente privada de toda pertinencia, la búsqueda de la totalidad se descubre entonces como un proyecto cuya variedad se vuelve irónicamente contra quien lo alimenta. Intotalizable, lo real pone incesantemente a prueba todo fantasma de señorío. Ello es la "alegría un poco melancólica" de su ironía.

Sacar lecciones del carácter irónico de lo real, es decir, de su temporalidad irreversible y acontecedera, esencialmente indomeñable, es abrirse a la descripción de un mundo como fenómeno intotalizable. Pero para esto todavía es necesario renunciar a querer sancionar, de una vez por todas, el sentido. No es que no lo haya y que todo sea absurdo, pues una propuesta como esta niega tanto la pertinencia del compromiso humano como el trabajo del espíritu de los pueblos, la construcción de las civilizaciones que ellos desarrollan y organizan, en suma, resolverse por un no-sentido es ya sancionar, negativamente, el sentido mismo del mundo. Respecto al individuo, esto constituye, como lo dice un personaje de la novela de Potocki, "el gran enigma del corazón humano", a saber, "que nadie hace lo que quiere hacer. Aquel que no ve la dicha más que en el matrimonio, se pasó la vida haciendo una elección y muere célibe. Aquel otro que juró no tener jamás mujer, se casa y se vuelve a casar"19. Pues bien, lo que vale aquí para la vida afectiva del individuo, lo compromete existencialmente de manera íntegra. Existir es comprender, a pesar de uno mismo, que lo real siempre denuncia mis proyectos -y esto, cuando irónicamente no los desmiente-, de suerte que jamás puedo estar seguro ni de su necesario fracaso, ni de su necesario logro. 
Existir es hacer frente a un real que uno no esperaba -y que desde entonces no cabe esperar, pues la asistematicidad de su manifestación le es originaria.

De cara a este intotalizable, las visiones populares del mundo y los sistemas filosóficos, por grandes que sean sus diferencias, se reúnen en una misma tentación y en un mismo deseo de unidad. Tanto para el uno como para el otro, es necesario decidir por un sentido y totalizar las perspectivas. Lo que los hace, entonces, poco sensibles a la "alegría un poco melancólica” de la ironía. Hegel, como se sabe, detesta la ironía. Identificándola con el romanticismo de Friedrich von Schlegel, ve en ella una renuncia al espíritu serio que la búsqueda de la racionalidad requiere. Incluso la ironía socrática le parece tan huera y vana que la concibe como aquello a lo que Platón ha debido renunciar para acceder a las Ideas. Y cuando publica, en 1828, una elogiosa reseña de las obras póstumas de su colega y amigo Karl Solger, se siente todavía obligado a sostener como material despreciable, o influencia nefasta, su profundo pensamiento de la ironía. Y con razón, porque la ironía, si no es reducida a un rasgo de espíritu o a un modo de comportamiento, no se deja aprehender al interior de una totalidad significante, aunque esta sea dialéctica. Toda dialéctica apunta, en efecto, a una síntesis, y todo sistema es reconciliador. Pero la "alegría un poco melancólica" no es ni melancólica ni agradable; siendo indecidible su sentido de ser, lo real, en ella, permanece intotalizable.

Es por esto que, en el último parágrafo de Totalidad e Infinito, Lévinas recuerda hasta qué punto una crítica de la totalidad es también una crítica de lo que la tradición filosófica, desde los griegos, no ha dejado de enrostrar: a saber, el Ser y lo trágico. Como señala Lévinas: "En las antípodas del sujeto viviente en el tiempo infinito de la fecundidad, se sitúa el ser aislado y heroico que produce el Estado por sus virtudes viriles. Aborda la muerte por puro coraje, cualquiera sea la causa por la cual muere. Asume el tiempo finito, la muerte-fin o la muerte-transición que no sanciona la continuación de un ser sin continuidad. La existencia heroica, el alma aislada puede salvarse buscando por sí misma una vía eterna como si su subjetividad pudiera no volverse contra ella misma al volver a sí en un tiempo continuo, como si, en este tiempo continuo, la identidad no se afirmase como una obsesión, como si en la identidad que sigue estando en el seno de los más extravagantes avatares, no triunfase el aburrimiento, el fruto de la triste falta de curiosidad que adquiere proporciones de inmortalidad" 20 .

La existencia heroica es la existencia que, no teniendo en cuenta lo que se vuelve contra sí al volver a sí, ignora la ironía. Es una existencia trágica, destinal. Y de hecho, es sorprendente que el momento de emergencia de la filosofía, en la Grecia antigua del siglo $\mathrm{V}$ antes de nuestra era, sea igualmente aquel de la tragedia, cuyo modelo ha marcado tan profundamente su evolución hasta Hegel, Hölderlin o Nietzsche. Contestar la primacía de

20 LÉVInAs, Emmanuel, Totalité et Infini, Essai sur l'extériorité, [1961], Kluwer Academic Publishers, Dordrecht, 1988, p. 284. La traducción al español está a cargo de Miguel García-Baró, Totalidad e Infinito, Sígueme, Salamanca, 2013. 
la ontología, en tanto que esta es, como dice Lévinas, un pensamiento de la totalidad, es también, por tanto, contestar la pertinencia del modelo heroico-trágico de la existencia, tal como parece surgir de la confrontación con la muerte, con el ser-hacia-la-muerte. Declarar trágico el sentido de ser, significa, en efecto, querer totalizarlo. Sin embargo, pensar lo infinito de lo intotalizable no es, a la inversa, abrirlo a un pensamiento de lo cómico y de la comedia de la vida.

Por esto, las nociones de revelación y de paz que Lévinas ha querido introducir en la filosofía no significan nada de esto. Es porque un pensamiento de lo que se vuelve contra sí al volver a sí, un pensamiento de la ironía no convierte el carácter intotalizable de lo real en una remisión a la tragedia o, a la inversa, a la comedia del mundo. La una y la otra son maneras de cerrar lo abierto. "La ironía - escribe certeramente Jankélévitch-, so pena de encallar, debe zigzagear peligrosamente entre el Caribdis del juego y el Escila de lo serio: la primera de estas trampas es el deslizamiento de lo irónico en lo lúdico, la segunda la caída de la alegoría en la ingenua tautegoría; tan pronto la ironía sucumbe al vértigo de la ambigüedad por el vaivén alocado entre letra y espíritu, como adhiere a la letra deseosa del equívoco por una elección unívoca"21. Ahora bien, tanto tragedia como comedia permanecen elecciones unívocas. Por esto, siendo superior a una u otra,-que no son más que maneras de decidir sobre el sentido deteniéndolo-, lo tragicómico puede ser la expresión misma de lo intotalizable.

El Littré nos dice que lo tragicómico es aquello que "se dice de algún accidente enfadoso con tinte cómico". Es tragicómica la aventura de aquel que, sacudido por un incidente benigno o por una torpeza, se encuentra finalmente en una situación cargada de desventaja. Como se suele decir, uno se reiría si las consecuencias no fueran tan enfadosas. Pero a esta primera definición, el Littré agrega una segunda. Tragicómico se dice igualmente "de lo irrisorio de las personas". Ahora bien, estos dos momentos también los encontramos en el género teatral epónimo, aunque, en general, la relación de lo trágico con lo cómico se invierte. Por ello, hablar de una situación de existencia tragicómica es insistir, finalmente, en su realidad dolorosa. Sin embargo, la comedia trágica, como lo dice también el Littré citando a Fontenelle, es una "pieza de teatro que mantiene de la tragedia el tema y los personajes, y de la comedia los incidentes y el desenlace".

Esto sucede en El Cid de Cornelio, obra que sirve aquí de referencia y cuyo subtítulo original (en 1636) es "comedia trágica", donde se trata también de pensar un fin dichoso. Así, Jimena terminará por desposar a su hombre amado, Rodrigo, aunque éste, obedeciendo a una errada petición de su padre, habrá provocado la muerte del padre de ella en un duelo. La situación es trágica, durante largo tiempo incierta, pero finalmente representada como feliz. Es necesario notar también que si ella lo es - ¿pero lo es verdaderamente sabiendo que al final de la pieza, que ulteriormente Cornelio nombrará tragedia, dejamos a 
los amantes y futuros esposos antes que hayan probado, por el hecho de vivir juntos, los incidentes de aquel acto?- si ella es, pues, feliz, esta situación no es, sin embargo, cómica.

En la comedia trágica lo cómico es el momento más delicado de significar, pues si debe mantenerse para evitar verter íntegramente el drama en la tragedia, no puede resolverse simplemente en una manifestación de dicha, alcanzada finalmente de una vez por todas. Ahí está el primer peligro que la acecha. Pero hay un segundo peligro, no menos grande: el de ser confundido con la bufonería o lo grotesco. En el primer caso, lo trágico se disuelve, y lejos de conducirnos a la incertidumbre de la vida, el feliz desenlace nos remite a una dialéctica en la cual el mal no es más que un momento del bien, y que hace de la vida una prueba. Tal es también el caso en esa comedia trágica de Shakespeare, por lo demás tan admirable, que es La tempestad, de 1611. Aquí, todo comienza por una traición: aquella de la que se hace culpable Antonio ante su hermano Próspero, duque de Milán. Preocupado de profundizar en el estudio de las artes liberales, Próspero lo deja temporalmente a cargo de los asuntos de su ducado. Sucede, pues, que Antonio, no resistiendo a la atracción del poder, expulsa a su hermano y su sobrina abandonándolos en el mar, a la suerte de las olas que los arrastrarán finalmente a una isla. Pero cuando Antonio, acompañado del rey de Nápoles, se encuentre a su vez en el mar, Próspero, ayudado por la magia, provoca una tempestad que los hace encallar - a ambos- en la misma isla. Esta isla se convertirá, de algún modo, después de una explicación, en la isla de la reconciliación.

Ciertamente, el extraordinario onirismo de esta pieza expresa admirablemente la extensión de la fragilidad humana, tanto como la ironía de las situaciones, jamás verdaderamente estabilizadas -como lo sugiere, por otro lado, el epílogo final-. Así, se enuncia una antropología barroca que hace jugar inversiones e incertidumbres. Shakespeare lo expresa en sus versos, como ningún otro: "Nuestra es la maraña / con la que las imágenes se tejen, y nuestra pequeña vida / está cercada por el sueño"22. Por tanto, lo tragicómico solo es aquí materia de una prueba sobre montada. Por ello, como dice el último verso de otra comedia trágica de 1604 o 1605: A buen fin no hay mal principio, "las amarguras del pasado hacen más dulce lo venidero" ${ }^{23}$.

Sin embargo, una pieza anterior como La vida de Enrique V (de 1599) -que aún cuando se nutre de crónicas históricas es fruto de la imaginación de Shakespeare-, es quizá, más que cualquiera otra, una verdadera comedia trágica. En ella, todo no es más que irónico volcamiento. El rey de Inglaterra declara la guerra a Francia para sustraer de este reino a un usurpador. Pero haciendo esto, no consigue más que exportar un conflicto que deshon-

22 Shakespeare, William, La tempête, IV, 1, v. 156-158; trad. de V. Bourgy, in Euvres complètes, Tragicomédies t. II, Robert Laffont, Paris, 2002, p. 493. Entre otras traducciones al español, destacamos la de Ángel-Luis Pujante, La tempestad, Espasa Libros, Madrid, 2010.

23 «The bitter past, more welcome is the sweet». Cfr. Shakespeare, W., Tout est bien qui finit bien, V, 3, v. 327, in Euvres complètes, Tragicomédies, t. I, Robert Laffont, Paris, 2002, p. 582. Entre las traducciones existentes, destacamos la de R. Martínez Lafuente y Gemma Moral, A buen fin no hay mal principio, RBA, Madrid, 2003. 
ra a Inglaterra. La guerra es justa, pero no muestra más que la miseria de los soldados en andrajos, víctimas de disentería. Azincourt es una víctima, pero el inglés que le arrastra y triunfa como héroe muere antes de poder ser coronado rey de Francia. Y si la dimensión cómica de la pieza es a veces lanzada a los chistes grotescos de personajes bufones, tales como Falstaff y sus compañeros, ella no queda reducida a esto. Por una parte, los bufones están perdidos; por otra, la dimensión cómica de las situaciones está asegurada por la incomprensión que se manifiesta entre los personajes. Aquí una princesa francesa intenta, más mal que bien, aprender inglés; allá un galés con fuerte acento intenta, lo que no es más simple, hacerse comprender por un inglés ${ }^{24}$. En suma, por todos lados, y más allá incluso de los momentos cómicos, reina el malentendido; malentendido que Jankélévitch supo identificar como una forma irónica mayor del yo-no-sé-qué. "Esa disimetría de una falsa verdad que con razón o sin ella, haciendo bien o no, que refleja tan bien nuestra condición ordinaria, es el principio del malentendido" 25 .

Y es que tal es la esencia, más que de la tragedia cómica teatral, de lo tragicómico de la existencia. El teatro es, en efecto, un arte de la representación, y en esto obedece las más de las veces a su exigencia, ya sea de hacer ver lo que muestra resaltando y engrandeciendo sus rasgos, ya sea concentrando su significación en un sentido u otro. Pero la existencia no es aquello que ponemos a distancia en el espacio de la representación, ella es de lo que hacemos prueba en tanto nos pone a prueba. En ella, gozo y sufrimiento se alternan, y si sucede que estos se entremezclan y comparten el lugar, ello es como el agua y el aceite: no se confunden, no se totalizan. Hay verdaderos sufrimientos y verdaderos goces, y la presencia de los unos no significa la desaparición o incluso la compensación de los otros; en tal caso, quedan asimilados como pérdida momentánea en el seno de un provecho de conjunto. Tampoco lo tragicómico es una categoría moral segunda de la existencia. No deriva de la comedia o de la tragedia supuesta de la vida. Lo tragicómico es la ambigüedad originaria que las hace posible. Es precisamente lo que, pesando con todo su peso, y de un peso que bien podría ser el más cargado, revela su carácter tan irónico como intotalizable.*

24 Shakespeare, W., La vie d'Henri V, cfr. IV, 7 et III, 4, trad. de J.-Cl. Sallé, in Euvres complètes, Histoires t. I, Robert Laffont, Paris, 1997, pp. 837-838 y 893. Entre las traducciones al español, destacamos la de José-María Valverde, Enrique V, Planeta, Barcelona, 1988.

25 JankéLÉvitch, V., Le je-ne-sais-quoi et le Presque-rien, T. 2, Seuil, Paris, 1980, p. 185.

*Artículo recibido: 26 de diciembre de 2013. Aceptado: 2 de marzo de 2014. 


\section{Bibliografía}

JANkÉLÉVITCH, V., L’ironie ou la bonne conscience, PUF, Paris, 1950.

LÉvinas, E., Totalité et Infini, Essai sur l'extériorité, [1961], Kluwer Academic Publishers, Dordrecht, 1988.

Maldiney, H., Regard Parole Espace, L’Age d'Homme, Lausanne, 1973.

Minder, R., Un poète romantique allemand. Ludwig Tieck, Les Belles Lettres, Paris, 1936.

Paul, J., Cours préparatoire d'esthétique, L'Age d'Homme, Lausanne, 1979 (traducción de Lang, A.-M y Nancy, J.-L.)

Pотоскі, J., Manuscrit trouvé à Saragosse, Paris, GF, 2008 (ed. de Rosset, F. y Triare, D.)

Shakespeare, W., La tempête, en CEuvres complètes, Tragicomédies, t. II, Robert Laffont, Paris, 2002 (traducción de Bourgy,V.)

, Tout est bien qui finit bien, en Euvres complètes, Tragicomédies $\mathrm{t}$.

I, Robert Laffont, Paris, 2002 (traducción de Bourgy, V.)

-----------------------, La vie d' Henri V, en Euvres complètes, Histoires t. I, Robert Laffont, Paris, 1997 (traducción de Sallé, J.-Cl.)

Tieck, L., La foire, Aubier, Paris, 1994 (traducción de Taubes, N.) 